\title{
Importância da motricidade fina nas aulas de Educação Física infantil: Uma revisão de literatura narrativa
}

Importance of children's fine motor skills in Physical Education classes: A narrative literature review

Importancia de la motricidad fina de los niños en las clases de Educación Física: Una revisión narrativa de la literatura

Recebido: 29/06/2021 | Revisado: 04/07/2021 | Aceito: 06/07/2021 | Publicado: 17/07/2021

Ivi Azevedo Feitosa Monteiro

ORCID: https://orcid.org/0000-0001-7915-4114 Centro Universitário Augusto Motta, Brasil

E-mail: monteiroivi@hotmail.com

Arthur Santos Lima da Cruz

ORCID: https://orcid.org/0000-0003-0845-7331

Centro Universitário Augusto Motta, Brasil

E-mail: arthurlogan021@hotmail.com

Rodrigo Santos

ORCID: https://orcid.org/0000-0002-1177-3135

Centro Universitário Augusto Motta, Brasil

E-mail: rodrigosantos.prof07@gmail.com

Rudson Santos da Silva

ORCID: https://orcid.org/0000-0002-8859-985X

Fundação Oswaldo Cruz, Brasil

E-mail: rss1917@gmail.com

Victor Gonçalves Corrêa Neto

ORCID: https://orcid.org/0000-0003-3133-1630

Centro Universitário Gama e Souza, Brasil

Universidade Estácio de Sá, Brasil

E-mail: victorgen@hotmail.com

Estêvão Rios Monteiro

ORCID: https://orcid.org/0000-0003-1866-553X

Centro Universitário Augusto Motta, Brasil Universidade Federal do Rio de Janeiro, Brasil E-mail: profestevaomonteiro@gmail.com

Marcelo José Colonna de Miranda ORCID: https://orcid.org/0000-0003-1552-9153

Centro Universitário Augusto Motta, Brasil Universidade Estácio de Sá, Brasil

E-mail: marcelocolonna71@gmail.com

\begin{abstract}
Resumo
O objetivo do presente estudo foi revisar as evidências sobre a contribuição das aulas de Educação Física na coordenação motora fina de estudantes da Educação Infantil. Foi realizada uma busca na base de dados do Google Acadêmico, sendo incluídos artigos publicados entre 2010 e março de 2021 e usando como descritores: "motricidade", "coordenação motora fina", "educação física", e "educação física infantil". Foram incluídos estudos originais, artigos de revisão e trabalho de conclusão de curso (TCC, Monografia, Dissertação e Tese), desde que redigidos na língua portuguesa. Foram incluídos três artigos, os quais majoritariamente tecem informações positivas sobre a Educação Física escolar para o desenvolvimento da motricidade. A motricidade fina desenvolvida na Educação Física Infantil tem importância até o fim da vida. Por isso, deve-se dar uma atenção especial a essas aulas, para que essas crianças, nessa faixa etária, quando se tornarem adultas, não venham a ter dificuldades em atividades cotidianas, por exemplo, atividades manuais em seu local de trabalho ou ao fazer uma ornamentação. Conclui-se que os professores de educação física infantil são os profissionais mais recomendados para desenvolver a motricidade fina, com ressalva de sempre estarem buscando conhecimento para se manterem atualizados.
\end{abstract}

Palavras-chave: Criança; Desempenho sensório-motor; Destreza motora; Educação física e treinamento.

\section{Abstract}

The purpose of the present study was to review the evidence of the contribution of Physical Education in fine motor coordination of Early Childhood Education students. A search was performed throughout Google Scholar database, 
including articles published between 2010 and March 2021 and using as descriptors: 'motor skills', 'fine motor skills', 'physical education', and 'child physical education'. Original and review research and final project (undergraduate, master and doctor thesis) were included and need to write in Portuguese. Three articles were included, which mostly weave positive information about school Physical Education for the motor skills development. Children motor skills development throughout Physical Education are important until the end of life. Therefore, special attention should be given to these classes, so that these children, in this age group, when they become adults, will not have difficulties in everyday activities, for example, manual activities in their workplace or when doing an ornamentation. It is concluded that children's physical education teachers are the most recommended professionals to develop fine motor skills, with the exception of always seeking knowledge to keep up to date.

Keywords: Child; Physical education and training; Psychomotor performance; Motor skills.

\section{Resumen}

El objetivo del presente estudio fue revisar la evidencia del aporte de la Educación Física en la coordinación motora fina de los estudiantes de Educación Infantil. Se realizó una búsqueda en la base de datos de Google Scholar, incluyendo artículos publicados entre 2010 y marzo de 2021 y utilizando como descriptores: 'habilidades motoras', 'habilidades motoras finas', 'educación física' y 'educación física infantil'. Se incluyó la investigación original y de revisión y el proyecto final (tesis de grado, maestría y doctorado) y es necesario redactarlo en portugués. Se incluyeron tres artículos, que en su mayoría tejen información positiva sobre Educación Física escolar para el desarrollo de habilidades motoras. El desarrollo de las habilidades motoras de los niños a lo largo de la educación física es importante hasta el final de la vida. Por lo tanto, se debe prestar especial atención a estas clases, para que estos niños, en este grupo de edad, cuando se conviertan en adultos, no tengan dificultades en las actividades cotidianas, por ejemplo, las actividades manuales en su lugar de trabajo o al realizar una ornamentación. Se concluye que los profesores de educación física infantil son los profesionales más recomendados para desarrollar la motricidad fina, con la excepción de buscar siempre conocimientos para mantenerse al día.

Palabras clave: Educación y entrenamiento físico; Desempeño psicomotor; Destreza motora; Niño.

\section{Introdução}

A educação infantil, primeira etapa da educação básica, tem como finalidade o desenvolvimento integral da criança (Lima e Santos, 2018) de até 5 (cinco) anos, em seus aspectos físico, psicológico, intelectual e social, complementando a ação da família e da comunidade. (LEI N 12.796 de 2013 art.29¹). Com tudo não se pode esquecer que a educação física infantil ela é complementada a educação familiar (Ferreira e Barreira, 2010), e a ação que ela sofre da sua comunidade de origem.

Godall e Hospital (2004) creditam a motricidade fina como a possibilidade de usar de forma eficiente e precisa os pequenos músculos, produzindo, assim, movimentos delicados e específicos. Este tipo de coordenação permite dominar o ambiente, propiciando manuseio dos objetos (Rosa Neto et al., 2010). Sabe-se que a educação infantil, deve atender as necessidades de desenvolvimento das crianças, deve proporcionar a plena realização de sua personalidade física, moral, social, emocional, e também desenvolver atividades favoráveis, em caráter recreativo, que, além disso, tem um efeito estimulante de alegria, sendo assim, percebe-se que atividades que influenciam nos processos superiores de raciocínio, favorecendo habilidades de reações prontas, prepara a criança para utilizar as possibilidades e vencer as dificuldades de agudez de pensamentos, e autodomínio, e noções de esquema corporal (Costa, 2013).

Verifica-se a utilização de músculos pequenos como os dos pés e mãos, ao desenhar, pintar ou manusear pequenos objetos, através dessa prática se desenvolve a motricidade fina, realizando-se assim movimentos mais leves, delicados e precisos, e desenvolvendo habilidades que as crianças levarão para o resto de suas vidas. Segundo Pellegrine et al. (2005) a aquisição de grande parte das habilidades motoras ocorre em casa, a partir da interação com a família. Entretanto, um bom número delas é adquirido na escola, nos primeiros anos de escolarização do educando.

Trabalhar a motricidade refinada das crianças é pré-requisito fundamental na Educação Infantil, pois prepara a criança para a aquisição da escrita posteriormente, isto é, na alfabetização (Costa, 2013). Para isso, é necessário disponibilizar para as crianças, materiais como massa de modelar, pintura a dedo, folhas de revistas que possa ser rasgada pelas crianças e depois

${ }^{1}$ Disponível em: < http://www.planalto.gov.br/ccivil_03/_ato2011-2014/2013/lei/112796.htm>Acessado em 16 de junho de 2021 às16:30 horas. 
coladas numa folha branca, tesoura e cola para recorte e colagem, macarrão em forma de argola, para serem enfiadas em barbante, e até mesmos, os brinquedos cantados, que agem como uma rica fonte pedagógica, afinal, brincar é a principal fonte de prazer das crianças (Carneiro, 2009). Brincar com movimento é o nosso campo de ação. Aprender com o corpo, aprender pelo movimento, brincar de mexer, lembrando que nessa fase infantil, o tato está em constante evolução. Uma atividade através do movimento, visando um desenvolvimento de capacidades básicas - sensoriais, perceptivas e motoras, propiciando uma organização adequada de atitudes adaptativas, atuando como agente profilático de distúrbios da aprendizagem.

Segundo Brito (2017), a motricidade fina parece ser capaz de desenvolver-se apenas após o momento temporal (cognitivo e psicomotor) onde a criança começa a demonstrar maior coordenação dos grandes grupamentos muscular, indicando assim um domínio psicomotor primitivo. A partir desta colocação, entende-se que a motricidade fina, é uma área dentro da motricidade global, porém só pode ser desenvolvida, quando a motricidade corporal por completo estiver dominada, já que a abordada necessita de maiores cuidados, por apresentar mais detalhes, consequentemente, exige mais atenção da criança, por isso, propõe-se lecionar através do jogo, e de atividades rítmicas e Expressivas, acompanhadas do respectivo suporte teórico da motricidade infantil, o desenvolvimento das habilidades motoras fundamentais, já que este depende da quantidade e qualidade de vivências motoras das crianças nas primeiras idades, para isso deve-se facultar conteúdos teóricos e práticos de forma a completar a formação na área da atividade física infantil.

A aula de educação física parece favorecer a maturidade da motricidade fina, como também auxiliar os aspectos gerais de formação, pois utilizam aspectos lúdicos, brinquedos, músicas, para envolvê-los nos sentidos motores, ao mesmo tempo iniciando um pensamento rápido para acompanhar o desempenho ditado pelo professor, trabalhando equilíbrio, lateralidade e reflexos. Investigou-se também, os órgãos de sentido que auxiliam na motricidade, sendo o tato, o principal deles, assim como a tonicidade, que “é uma tensão dos músculos, pela qual as posições relativas das diversas partes do corpo são corretamente mantidas e que se opõem as modificações passivas dessas posições”. (Coste, 1981, p 25).

A escola tem o papel de incentivar o desenvolvimento deste sentido, pois futuramente o auxiliará em funções básicas do cotidiano do cidadão, como escrever um texto, digitar uma mensagem, segurar um copo ou colocar um relógio. Foram identificadas algumas estratégias principais utilizadas na aula de educação física escolar para tal estímulo, são elas: Massinhas de modelar, para que as crianças tentem reproduzir algum desenho proposto (Um círculo, um balde, um boné, um celular), coisas do seu dia a dia. Contornar com caneta colorida, um desenho feito com caneta preta, e depois colori-lo com outras cores não utilizadas, para que ele perceba as linhas limítrofes do desenho, se privando de borrar. Colar palitinhos de picolé, formando um objeto que desejarem, recorte de revistas, algodão, entre outros. Todas essas atividades fazem parte de uma gama de recursos pedagógicos, com o objetivo de desenvolver não só a motricidade fina, mas também a imaginação, a parte lúdica, deixando as tarefas mais alegres, para que sintam prazer em realizá-las, até porque, fomos crianças e sabemos que na infância, não se quer fazer uma atividade, se esta não lhe der diversão. "As pessoas engajadas na Educação Infantil percebem a necessidade das atividades de Movimento para as crianças. Essas atividades quando são desenvolvidas nas escolas infantis, na prática, restringem-se a brincadeiras nos aparelhos do parque, jogos de correr, brincadeiras livres nos espaços internos e externos da escola e brincadeiras de rua, todas elas permeando o objetivo de recreação. (Magalhães, 1994, p 15) Percebe-se que tudo que envolve a educação infantil, gira em torno da recreação, do gênero lúdico, onde a criança vai expressar toda sua criatividade, sentimento, prazer, no simples ato de realizar atividade, e isso faz toda a diferença. Devemos acreditar na evolução do ser humano por completo, com uma base forte na infância, com o aspecto sensório-motor bem desenvolvido, adquirindo assim, maiores contextos da motricidade durante sua vida. As escolas e seus professores, devem continuar buscando novos métodos para aprofundar ainda mais o estudo da motricidade, e assim continuaremos em progresso com os futuros cidadãos que estamos formando. 
A motricidade fina trabalhada na educação física infantil é de suma importância para que tanto as crianças quanto os adultos não tenham dificuldades na sua vida cotidiana para realizar tarefas como, por exemplo: atividades manuais em seu local de trabalho, ou ao fazer uma ornamentação etc. Alguns estudos nos mostram que até mesmo os adultos, realizam uma tarefa mais rápida e com melhor qualidade em seu trabalho, quando sentem prazer ao realizá-la, não só por esperar um pagamento em dinheiro ao final da tarefa, mas por diminuir o peso da obrigação, não ter a preocupação em terminar logo, por aquilo estar incomodando, isso gera cansaço, stress, caos psíquico, já sendo prazerosa, entende-se que é gratificante para este cidadão cumprir suas metas, sem sofrer por isso. Imaginemos então, como seria para uma criança, realizar uma tarefa de seu porte, sendo esta cansativa. Não dá pra imaginar não é mesmo? Por isso cabe à nós professores, cuidarmos do aspecto lúdico deste ser. Temos uma grande variedade de possibilidades que podem auxiliar e facilitar a maturidade da motricidade fina nas crianças da educação física infantil, como por exemplo: músicas gestuais, brinquedos pequenos, massinha, ligar pontos, pintar dentro dos limites dos desenhos, entre outros.

Dessa forma, o objetivo do presente estudo foi revisar as evidências sobre a contribuição das aulas de Educação Física na coordenação motora fina de estudantes da Educação Infantil.

\section{Metodologia}

\subsection{Tipo de estudo}

O estudo em tela é uma pesquisa de cunho de revisão de literatura (Estrela, 2018).

\subsection{Seleção dos artigos}

A busca foi feita na base de dados do Google Acadêmico, sendo incluídos artigos publicados entre 2010 e março de 2021. Durante a pesquisa, descritores como "motricidade", "coordenação motora fina", "educação física", e "educação física infantil" foram utilizados nos campos de busca das bases de dados.

Os estudos encontrados com essas palavras-chaves foram avaliados e selecionados seguindo os seguintes critérios de inclusão: a) artigo original, b) artigos de revisão, c) trabalho de conclusão de curso (TCC, Monografia, Dissertação e Tese) e d) estar redigido na língua portuguesa. Foram descartados artigos que tenham realizados intervenção médica.

Os resumos dos artigos foram lidos para que os preceitos elencados acima fossem aplicados. Selecionando assim, os artigos que se destinaram a ser lidos na íntegra. Os artigos selecionados têm como aplicabilidade a avaliação da motricidade durante uma aula de educação física escolar.

\section{Resultados e Discussão}

A Figura 1 traz o flowchart indicando todas as etapas da busca. Foram encontrados um total de 175 artigos e, após passarem pelos critérios de inclusão e exclusão, foram analisados 3 artigos no total: Godtsfriedt (2010), Freitas (2015) e Ribeiro (2018). O Quadro 1 traz a síntese das principais informações extraídas dos estudos. 
Figura 1. Etapas de busca.

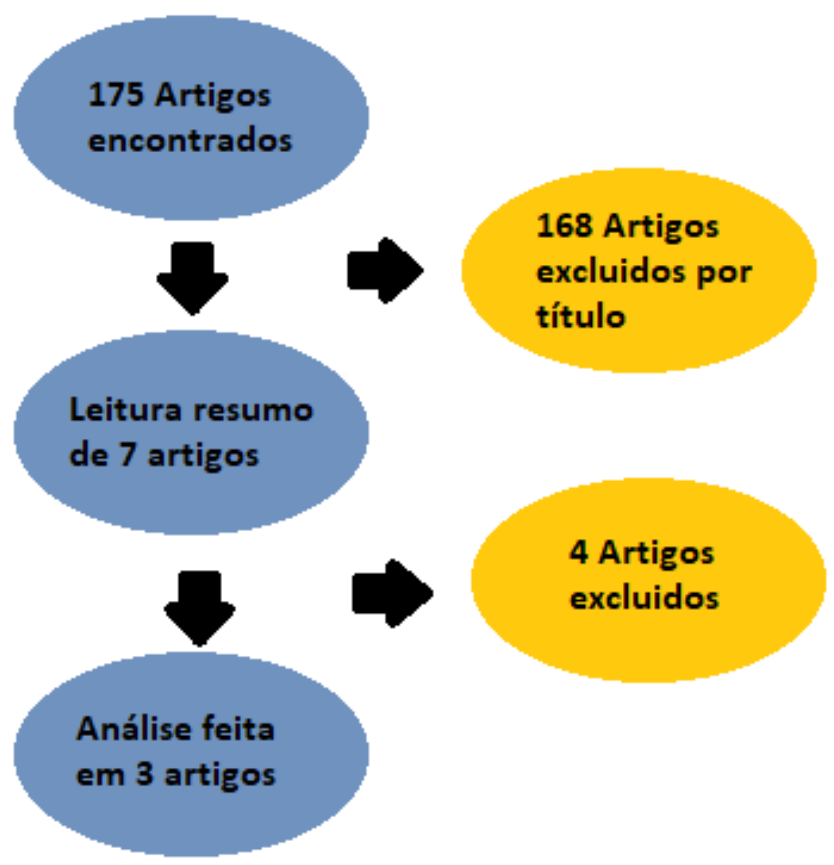

Fonte: Autores.

Quadro 1 - Descrição dos estudos selecionados.

\begin{tabular}{|l|l|l|l|}
\hline \multicolumn{1}{|c|}{ Autor/Ano } & \multicolumn{1}{|c|}{ Título } & Tipo de Estudo & \multicolumn{1}{c|}{ Conclusões } \\
\hline $\begin{array}{l}\text { Godtsfriedt } \\
(2010)\end{array}$ & $\begin{array}{l}\text { Desenvolvimento motor: } \\
\text { motricidade global e fina }\end{array}$ & Pesquisa bibliográfica & $\begin{array}{l}\text { Um programa de Educação Física bem estrutura desde as } \\
\text { primeiras idades pode contribuir notavelmente para o } \\
\text { desenvolvimento motor sem pretender acelerar este } \\
\text { desenvolvimento. Porém, para exercer esta influência sem o } \\
\text { perigo de cometer erros no processo de ensino, todo } \\
\text { educador deve alimentar-se da informação necessária sobre a } \\
\text { evolução do desenvolvimento, seus avanços e retrocessos } \\
\text { (Gonzáles Rodrigues, 2005). }\end{array}$ \\
\hline Freitas (2015) & $\begin{array}{l}\text { O papel da Educação Física } \\
\text { no desenvolvimento motor } \\
\text { das crianças do ensino } \\
\text { globalizado }\end{array}$ & $\begin{array}{l}\text { Transversal } \\
\text { A presença de um profissional de Educação Física nas séries } \\
\text { das propories iniciais sendo de extrema relevância para um } \\
\text { melhor desenvolvimento motor dos estudantes. }\end{array}$ \\
\hline
\end{tabular}




\begin{tabular}{|c|c|c|c|}
\hline Ribeiro (2018) & $\begin{array}{l}\text { A contribuição das } \\
\text { atividades lúdicas no } \\
\text { desenvolvimento da } \\
\text { coordenação motora ampla } \\
\text { e fina na Educação Infantil }\end{array}$ & Descritivo & $\begin{array}{l}\text { Os professores de Educação Física consideram importante } \\
\text { trabalhar com atividades lúdicas, pois através desses } \\
\text { estímulos ocorre a melhora do desenvolvimento da } \\
\text { coordenação motora ampla e fina dos estudantes da } \\
\text { Educação Infantil. Elas trazem benefícios para o } \\
\text { desenvolvimento motor, porém é indispensável que o } \\
\text { professor tenha o conhecimento de seus alunos e desenvolva } \\
\text { ações que contribuem nesse processo. E isso, é possível } \\
\text { através da utilização de estratégias de ensino que estimulem } \\
\text { a coordenação ampla e fina com jogos e brincadeira } \\
\text { pertinentes. }\end{array}$ \\
\hline
\end{tabular}

Fonte: Autores.

O objetivo do presente estudo foi revisar as evidências sobre a contribuição das aulas de Educação Física na coordenação motora fina de estudantes da Educação Infantil. Neste sentido, Godtsfriedt (2010) indica que uma adequada estruturação das aulas de Educação Física escolar nas idades iniciais parece ajudar na maturidade da coordenação motora fina e melhorar o desenvolvimento psicomotor. Porém, para que tais efeitos ocorram de forma positiva, os profissionais devem ficar em alerta para fornecer subsídios adequados para essa maturação, permitindo assim que avanços psicomotores aconteçam (Kishimoto et al., 2018). O professor deve buscar sempre se atualizar, verificando qual a melhor ferramenta para se trabalhar (Piaget, 1978; Vygotsky, 1998). Kishimoto et al. (2018) conduziram um trabalho comparativo e observaram que a técnica adjuvante de origami parece influenciar significativamente o desempenho da coordenação motora fina.

Segundo Ribeiro (2018) As atividades lúdicas, contribuem na melhora do psicomotora e maturidade da coordenação motora global e fina dos educandos da Educação Infantil, trazendo benefícios para o desenvolvimento motor, porém é indispensável que o professor tenha o conhecimento de seus alunos e desenvolva ações que contribuem nesse processo. E isso, é possível através da utilização de estratégias de ensino que estimulem a coordenação ampla e fina com jogos e brincadeiras pertinentes (Dallabona e Mendes, 2004; Santos, Castro e Miranda, 2020; Silva, Souza e Coutinho, 2020). Então para a maturidade psicomotora (motricidade fina) é necessário que o professor detenha conhecimento para saber desenvolvê-la e também observar seus alunos de forma que detecte os déficits e planeje suas aulas de forma que atenda a essas necessidades.

Em sua pesquisa Freitas (2015) conclui que a presença de um profissional de educação física nas séries iniciais proporciona melhor proficiência motora nos alunos das séries iniciais sendo de extrema relevância para um melhor desenvolvimento motor dos estudantes. Através dos resultados observados nos estudos de Ribeiro (2018) e Freitas (2015) que o professor necessita conhecer essa etapa do desenvolvimento para obter melhor resultado no desenvolvimento motor fino os alunos, porém o segundo autor percebeu que esse conhecimento é encontrado em professores de educação física infantil, e que os alunos que não têm aula com professores de Educação Física infantil apresentam a maturidade da motricidade fina freadas quando comparadas aos de alunos que têm.

Observada uma dificuldade em encontrar conteúdos que abordassem diretamente a motricidade fina nas aulas de educação física infantil, os artigos selecionados quando não apresentaram a conexão dos dois vértices dessa pesquisa que são as aulas de educação infantil e a motricidade fina, ao menos um dos temas foi observado. Evidenciou-se uma necessidade de que haja mais pesquisas voltadas a esse tema fundamental para a vida humana, pois como já mencionado a motricidade fina aprendida na infância é fundamental para na fase adulta se realizar tarefas do cotidiano.

\section{Considerações Finais}


A motricidade fina desenvolvida na Educação Física Infantil tem importância até o fím da vida. Por isso, deve-se dar uma atenção especial a essas aulas, para que essas crianças, nessa faixa etária, quando se tornarem adultas, não venham a ter dificuldades em atividades cotidianas, por exemplo, atividades manuais em seu local de trabalho ou ao fazer uma ornamentação. Conclui-se que os professores de educação física infantil são os profissionais mais recomendados para desenvolver a motricidade fina, com ressalva de sempre estarem buscando conhecimento para se manterem atualizados. Assim sendo, os autores sugerem que novos estudos sejam desenvolvidos nesta temática a fim de observar mais detalhadamente o comportamento motor fino em crianças, permitindo assim que sejam desenvolvidas estratégias que auxiliem o seu desenvolvimento ao longo das aulas de Educação Física escolar.

\section{Agradecimentos}

Os autores agradecem a participação de todos os voluntários dessa pesquisa.

\section{Referências}

Brito, M. C.; Carrara, K. (2010). Alunos com distúrbios do espectro autístico em interação com professores na educação inclusiva: descrição de habilidades pragmáticas. Rev Soc Bras de Fonoaudiol, 15 (3), 421- 429.

Brito, M. C. (2017). Estratégias Práticas de Intervenção nos Transtornos do Espectro do Autismo. E-book. Saberautismo.

Carneiro, K. T. (2009). O jogo na Educação Física escolar: uma análise sobre as concepções atuais dos professores. Trabalho de conclusão de curso de Mestrado em Educação Escolar. Universidade Estadual Paulista.

Costa, A. F. A. (2013). O desenvolvimento da motricidade fina: um estudo de intervenção com crianças em idade pré-escolar. Trabalho de conclusão de curso de Mestrado em Educação Pré-Escolar. Instituto Politécnico de Viana do Castelo.

Coste, J. C. (1981). A Psicomotricidade. $2^{\circ}$ ed. Editora Zahar.

Dallabona, S. R.; Mendes, S. M. S. (2004). O lúdico na educação infantil: jogar, brincar, uma forma de educar. Revista de divulgação técnico-cientifica do ICPG, 1 (4), 107-112.

Estrela, C. (2018). Metodologia Científica: Ciência, Ensino, Pesquisa. Editora Artes Médicas.

Ferreira, S. H. A., Barrera, S. D. (2010). Ambiente familiar e aprendizagem escolar em alunos da educação infantil. Psico, 41 (4), $462-472$.

Freitas, A. O. (2015). O papel da educação física no desenvolvimento motor das crianças do ensino globalizado. Trabalho de conclusão de curso de PósGraduação em Educação Física Infantil e anos iniciais. Universidade Federal de Santa Catarina.

Godall, T.; Hospital, A. (2004). 150 propostas de atividades motoras para a educação infantil (de 3 a 6 anos). Editora Artmed.

Godtsfriedt, J. (2010). Desenvolvimento motor: motricidade global e fina. Revista Digital - Buenos Aires, 15 (143).

Gonzáles Rodrigues, C. (2005). Educação física infantil: motricidade de 1 a 6 anos. Editora Phorte.

Kishimoto, S. T.; Marco, A.; Soares, D. B.; Pontin, A. L. (2014). Educação Física escolar e a técnica de origami na educação infantil. Pensar a Prática, 17 (2), $359-376$.

Lima, J. dos S.; Santos, G. L. dos. (2018). Valores, educação infantil e desenvolvimento moral: concepções dos professores. Educ Form, 3 (2), $153-170$.

Magalhães, M. C. C. (1994). Etnografia Colaborativa e Desenvolvimento de Professor. Trab Ling Apl, 23, 71-78.

Pelegrine, A. M.; Souza Neto, S.; Bueno, F.; Alleoni, B.; Motta, A. (2005). Desenvolvendo a coordenação motora no ensino fundamental. São Paulo. Núcleos de Ensino da Unesp: artigos 2005 [recurso eletrônico] / organizadores Laurence Duarte Colvara, José Brás Barreto de Oliveira - Dados eletrônicos (vol. 1 - p. 178-191) - São Paulo: Cultura Acadêmica: Universidade Estadual Paulista, Pró-Reitoria de Graduação.

Piaget, J. (1978). A formação do símbolo na criança: imitação jogo e sonho, imagem e representação. Rio de Janeiro: Zahar.

Rosa Neto, F.; Weiss, S. L. I.; Santos, A. P. M.; Amaro, K. N. (2010). Analysis of the internal consistency of fine motricity test from EDM (Motor Development Scale). Journal of Physical Education, 21 (2), 191-197.

Santos, R. M.; Castro, T. R.; Miranda, A. C. (2020). Intervenção pedagógica com jogos e brincadeiras na educação infantil. Braz J of Develop, 6 (6), 3738637396.

Silva, R. M. C.; Souza, G. L.; Coutinho, D. J. G. (2020). Coordenação motora infantil - desenvolvimento no seu tempo. Braz J of Develop, 6 (7), 5410254116.

Vygotsky, L. (1998). A formação social da mente. São Paulo: Martins Fontes. 
Research, Society and Development, v. 10, n. 8, e51010817684, 2021

(CC BY 4.0) | ISSN 2525-3409 | DOI: http://dx.doi.org/10.33448/rsd-v10i8.17684 